\title{
Malonaldehyde formation is not a suitable screening test to detect oxidation in human neutrophils
}

\author{
RONALD G STRAUSS
}

From the Department of Pediatrics, University of Iowa Hospitals and Clinics, Iowa, USA

SUMMARY The thiobarbituric acid (TBA) assay for measuring malonaldehyde (MDA) has bee applied to many tissues as a simple means of detecting oxidative damage and prostaglandin synthesis Human neutrophils, cells known to produce prostaglandins and toxic metabolites of oxygen, wer studied to determine if this assay could provide a suitable, rapid, screening test to recognise states ơf metabolic activation, to monitor prostaglandin synthesis, or to identify the presence of oxidative damage. Malonaldehyde could not be detected after a variety of manipulations. Thus, it seem§ unlikely that the thiobarbituric acid assay, as performed here, will be useful for evaluating oxidative damage in human neutrophils.

Tissues that have been incubated aerobically will react with thiobarbituric acid (TBA) to form a stable pink chromophore ${ }^{1}$ known as malonaldehyde (MDA), a secondary oxidation product of polyunsaturated fatty acids possessing at least 3 double bonds. ${ }^{2}$ Because of its simplicity and sensitivity ${ }^{3}$ the TBA assay has been applied to many tissues, cells and organelles to detect MDA as a marker of lipid peroxidation secondary to prostaglandin metabolism or as a consequence of oxidative damage. In platelets, for example, the presence of MDA is used as evidence of prostaglandin biosynthesis, ${ }^{4}$ as an indicator of oxidative damage during storage,,$^{5}$ and to identify states of heightened activity or aggregability. 6

Human neutrophils produce prostaglandins via both the cyclo-oxygenase and lipoxygenase pathways, ${ }^{78}$ particularly when activated by phagocytosis or similar soluble stimuli. Furthermore, activated neutrophils may experience self-inflicted oxidative damage. ${ }^{9}$ Thus, it is logical to assume that, as for platelets, MDA could serve as a convenient marker for activated or damaged neutrophils or both. Indeed, it was used recently for this purpose in studies of rat neutrophils. ${ }^{10}$ The purposes of this report, however, are to affirm previous findings that human neutrophils will not generate MDA under usual circumstances ${ }^{11}$ and to extend the earlier data by showing that the lack of MDA formation is not due to neutrophil-derived inhibitors. Thus, techniques that are more demanding than the simple TBA assay must be employed to detect prostaglandin metab-

Accepted for publication 16 December 1980 olism or oxidative damage or both in humaş neutrophils.

\section{Material and methods}

Studies were approved by the local committe@ governing human investigations and informe consent was obtained. Venous blood neutrophil were isolated by the sequence of dextran sedimentas tion, Ficoll-Hypaque centrifugation, and hypotonie lysis. ${ }^{12}$

Neutrophils were suspended in Krebs-Ringe phosphate buffer $(\mathrm{pH} 7 \cdot 4)$ to a concentration of $2 \times 10^{7} / \mathrm{ml}$. Non-phagocytic and phagocytic neutrog phils were prepared by incubating $1 \mathrm{ml}$ of neutro phil suspension with $1 \mathrm{ml}$ of either buffer or opsonê ised zymosan (neutrophil :zymosan $=1: 50$ ) at $37^{\circ} \mathrm{C}$ for $30 \mathrm{~min}$ with constant agitation. Phagocytig reactions of this type are known to generate largo quantities of the activated forms of oxygen. Reactions were halted by plunging the tubes into icen The entire reaction mixture was studied with the TBA assay, rather than simply the cell pellet, to be certain the TBA-reactive materials would be measured even if shed into the extracellular phase of the suspeno sion. ${ }^{11}$

MDA was detected by its reaction with TBA. Briefly, TBA reagent was prepared by dissolving $1.6 \mathrm{~g}$ TBA in $200 \mathrm{ml}$ of $0.025 \mathrm{~N}$ sodium hydroxidē and adjusting the $\mathrm{pH}$ to 2.8 with concentrate $\$$ sodium hydroxide. One $\mathrm{ml}$ of either the nons phagocytic or phagocytic neutrophil suspension was combined with $2 \mathrm{ml}$ of the TBA reagent, and the mixture was placed in a boiling water-bath fos 
$15 \mathrm{~min}$. Debris was then removed by centrifugation at $1000 \mathrm{~g}$ for $15 \mathrm{~min}$. The clear supernatant was placed into clean tubes and read in a spectrophotometer at $535 \mathrm{~nm}$. The spectrophotometer was zeroed with the TBA reagent. A standard curve was constructed using MDA prepared by the acid hydrolysis of TEP (1,1,3,3-tetraethoxypropane, Eastman Organic Chemicals, Rochester, NY). Equal volumes of TEP and $0.2 \mathrm{~N}$ hydrochloric acid were held at room temperature overnight. It was assumed that one molecule of TEP yields one molecule of MDA plus four molecules of ethanol when acidified. ${ }^{5}$ Volumes of this mixture containing 5,10 and $20 \mathrm{nmol}$ of TEP converted to MDA were reacted with TBA, and a standard curve was constructed (Figure).

\section{Results and discussion}

MDA, that was generated by acidifying TEP,

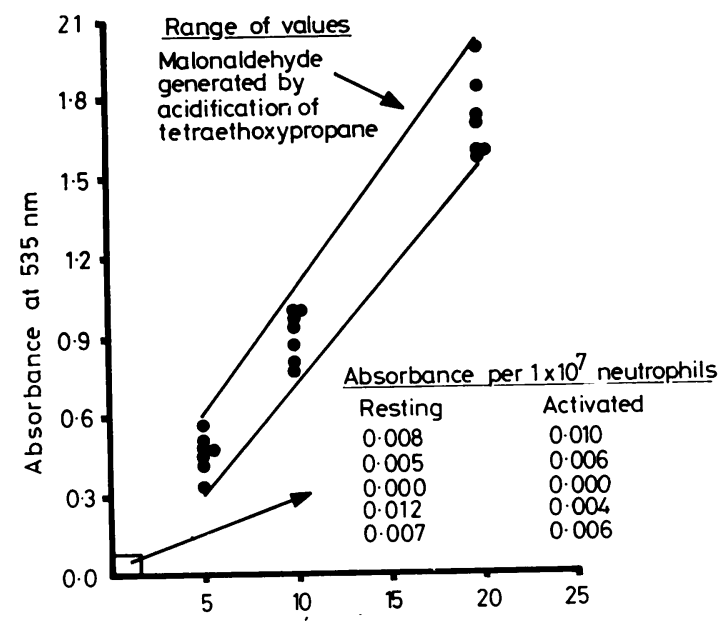

Malonaldehyde (nmol)

Malonaldehyde generated by the acidification of tetraethoxypropane was detected in a dose-related fashion by reaction with thiobarbituric acid. Literally no malonaldehyde was identified in samples of either non-phagocytic (resting) or phagocytic (activated) neutrophils as evidenced by the extremely low absorbance readings. reacted with TBA and was detected in dose-related fashion, however, neither resting (non-phagocytic) nor activated (phagocytic) neutrophils produced sufficient quantities of TBA-reactive material to permit accurate spectrophotometric measurement (Figure). It may be argued that insufficient neutrophil numbers were used. The modest concentration $\left(1 \times 10^{7} / \mathrm{ml}\right)$ was chosen because it represents a quantity of cells easily obtained from individual subjects. In attempts to detect TBA-reactive material, phagocytic reactions containing up to $4 \times 10^{7}$ neutrophils $/ \mathrm{ml}$ were studied. In addition, attempts were made to increase the sensitivity of the assay by using a spectrophotofluorometer with the excitation and emission wavelengths set at 515 and $553 \mathrm{~nm}$, respectively. ${ }^{14}$ Finally, neutrophils were exposed to varying concentrations $\left(10^{-4} M\right.$ up to $\left.3 \%\right)$ of hydrogen peroxide $\left(\mathrm{H}_{2} \mathrm{O}_{2}\right)$, to glucose-glucose oxidase (an enzyme system generating a continuous source of $\mathrm{H}_{2} \mathrm{O}_{2}$ ) and to xanthine-xanthine oxidase (a generator of $\mathrm{H}_{2} \mathrm{O}_{2}$, superoxide anion and hydroxyl radical) in the event that phagocytosis failed to produce sufficient oxidative damage. None of these treatments induced TBA-reactive material that could be detected spectrophotometrically after subtracting the absorbance of appropriate controls.

The possibility that human neutrophils inhibit the reaction of MDA with TBA or the production of colour was investigated as follows: (a) mixtures of non-phagocytic and phagocytic neutrophils were prepared, and pelleted by centrifugation; (b) MDA was generated by the acidification of TEP, and each neutrophil pellet was resuspended in $1 \mathrm{ml}$ of acidified TEP presumed to contain $20 \mathrm{nmol}$ of MDA; (c) this mixture was reacted with TBA, and the results were compared to the control $(1 \mathrm{ml}$ of acidified TEP reacted with TBA in the absence of neutrophils). Neither non-phagocytic nor phagocytic neutrophils were found to interfere with the development of colour in the reaction (Table).

In conclusion, the TBA assay designed to measure MDA failed to detect a state of metabolic activation or the presence of lipid oxidation products in human neutrophils. Thus, the assay as performed in this paper will not serve as a suitable screening test for

Neutrophils fail to interfere with the detection of malonaldehyde when measured as TBA-reactive material spectrophotometrically

\begin{tabular}{llll}
\hline Study No & $\begin{array}{l}\text { Malonaldehyde* } \\
\text { without neutrophils }\end{array}$ & $\begin{array}{l}\text { Malonaldehyde (+) } \\
\text { Non-phagocytic neutrophils }\end{array}$ \\
\hline 1 & $1 \cdot 894^{* *}$ & $\begin{array}{l}\text { Malonaldehyde (+) } \\
\text { Phagocytic neutrophils }\end{array}$ & $1 \cdot 862$ \\
2 & 1.904 & $2 \cdot 042$ & $1 \cdot 788$ \\
3 & $2 \cdot 124$ & $2 \cdot 092$ & $1 \cdot 918$ \\
4 & 1.942 & $1 \cdot 788$ & $2 \cdot 294$ \\
\hline
\end{tabular}

* $20 \mathrm{nmol}$ generated by acidification of tetraethoxypropane.

* optical density at $535 \mathrm{~nm}$. 
these conditions in human neutrophils, although it has been useful for platelets, mononuclear phagocytes and animal neutrophils.

This study was supported in part by grant No RO1 HD11964 and Research Career Development award No 1 KO4 HD00255 (awarded to Dr Strauss) from the National Institute of Child Health and Human Development, National Institutes of Health. Susie Reed typed the manuscript.

\section{References}

${ }^{1}$ Kohn HI, Liversedge M. On a new aerobic metabolite whose production by brain is inhibited by apomorphine, emetine, ergotamine, epinephrine, and menadione. $J$ Pharmacol 1944;82:292-304.

2 Dahle LK, Hill EG, Holman RT. The thiobarbituric acid reaction and the auto-oxidations of polyunsaturated fatty acid methyl esters. Arch Biochem Biophys 1962;98: 253-61.

${ }^{3}$ Chow CK. Nutritional influence on cellular antioxidant defense systems. Am J Clin Nutr 1979;32:1066-82.

4 Smith JB, Ingerman CM, Silver MJ. Malondialdehyde formation as an indicator of prostaglandin production by human platelets. $J$ Lab Clin Med 1976;88:167-75.

s Okuma M, Steiner M, Baldini M. Studies on lipid peroxides in platelets. 1. Method of assay and effect of storage. $J$ Lab Clin Med 1970;75:283-96.

- Stuart MJ. Platelet malonyldialdehyde formation: An indicator of platelet hyperfunction. Thromb Haemo 1979;2:649-55.

${ }^{7}$ Stenson WF, Parker CW. Metabolism of arachidonic acid in ionophore-stimulated neutrophils. $J$ Clin Invest $197 \overline{\bar{P}_{\hat{B}}}$ 64:1457-65.

${ }^{8}$ Waite M, DeChatelet LR, King L, Shirley PS. Phage cytosis-induced release of arachidonic acid from huma? neutrophils. Biochem Biophys Res Commun 1979;90:9842 92.

${ }^{9}$ Baehner RL, Boxer LA, Allen JM, David J. Auto-oxidation as a basis for altered function by polymorphonuclew leukocytes. Blood 1977;50:327-35.

${ }^{10}$ Harris RE, Boxer LA, Baehner RL. Consequence of vitamin-E deficiency on the phagocytic and oxidative. functions of the rat polymorphonuclear leukocyte. Bloofe 1980;55:338-42.

11 Stossel TP, Mason RJ, Smith AL. Lipid peroxidation human blood phagocytes. J Clin Invest 1974;54:638-45. $\omega$

${ }^{12}$ Strauss RG, Snyder EL, Wallace PD, Rosenberger TG. Oxygen-detoxifying enzymes in neutrophils of infants and their mothers. $J$ Lab Clin Med 1980;95:897-904.

${ }^{13}$ Strauss RG. Neutrophil assays as modified for infants. Clin Lab Immunol 1980;3:133-5.

${ }^{14}$ Ohkawa H, Ohishi N, Yagi K. Assay for lipid peroxides in animal tissues by thiobarbituric acid reaction. Anal Biochem 1979;95:351-6.

Requests for reprints to: RG Strauss MD, Department of Pediatrics, University of Iowa Hospitals and Clinics, Iowe City, Iowa 52242, USA. 